\title{
Design, Analysis and Manufacturing Polymer Fiber Reinforced Composite Helical Spring
}

\author{
Hadeer Abdul Rasol ${ }^{1}$, Mahmud Rasheed Ismail ${ }^{2}$, Abdul Rahman Najam ${ }^{3}$
}

\section{Authors affiliations: \\ 1) Mechanical Engineering \\ Dept., Al-Nahrain University, Baghdad, Iraq \\ hadeerrasol603@gmail.com}

2) Prosthetic and Orthotic Engineering Dept., Al-Nahrain University, Baghdad, Iraq mahmech2001@yahoo.com

3) Mechanical Engineering Dept., Al-Nahrain University, Baghdad, Iraq

abdulraman60@gmail.com

\section{Paper History:}

Received: $11^{\text {th }}$ March 2020

Revised: $19^{\text {th }}$ July 2020

Accepted: $25^{\text {th }}$ Sep. 2020

\begin{abstract}
In this work it had been focused on the possibility of replacement of steel spring in suspension system by fiber reinforced polymer composite that is responsible for light weight of spring which leads to reduces the weight of vehicle and improve fuel efficiency. This type of spring used in motor cycles, light weight vehicle. The design will be simulated by ANSYS workbench. Then, E-Glass fiber has been used to fabricate helical compression spring of $40 \%$ fiber volume fraction of glass. with polyester resin. The deflection of glass reinforced composite spring is more than steel spring but within permissible limit. weight of composite spring is reduced by $57 \%$ than of steel.
\end{abstract}

Keywords: Spring Design, Composite Material, Spring Analysis, Manufacturing Composite Spring.

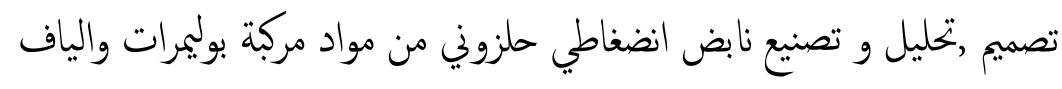

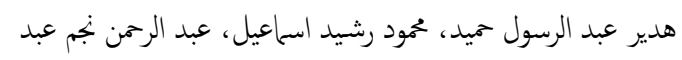

$$
\begin{aligned}
& \text { الملاصة: } \\
& \text { هذا البحث يتناول التركيز على امكانية استبدال الناض الفولاذي في نظام التعليق في العجلات بمواد مركه }
\end{aligned}
$$

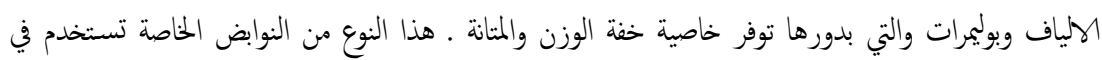

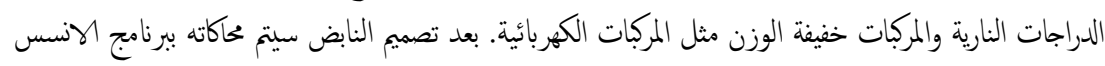

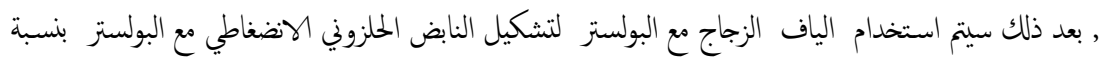

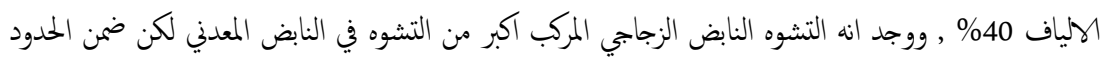

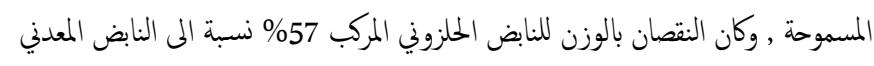

\section{Introduction:}

Now days, with industrial development that occur in automobile industry. Engineers and designers have resorted to introducing a new material into the manufacture of vehicle parts. The suspension system is composed of springs and shock absorbers which connect the wheels to the vehicle body. The easy and comfortable driving was depending on the efficiency of suspension system over the road harshness. The function of suspension system is responsible for keeping the wheels always in contact with the ground and vehicle roll is minimized. The suspension system consist of three major parts: firstly, a structure which substance the vehicle's weight and defines the suspension geometry, secondly, spring is an object which converts the kinematic energy to potential energy or vice versa, and a shock absorber that is a mechanical device designed to recede kinetic energy.[1] Spring is an elastic object whose function is to stock pilling energy when swerve by force and return equivalent amount of energy on being released.[2]. The purpose of this search was design helical compression spring and manufacture it by fibers and polyester to reduce the weight of spring on the other hand improved fuel consumption.

Many research has been focused on reducing weight of vehicle which leads to reduce fuel consumption and this may be done by substitution of steel spring by composite material. the later may be provide weight saving, high corrosion resistance ,creep resistance, provision energy, improving performance of shock absorber and low maintenance cost. but on the other hand, there are many problems of manufacturing of this type of composite material .[3]

Several papers were devoted to investigate the application of composite material in automobile. Ganesh Bhrimrao Javdhav .(2015). [4] this study discuss the feasibility of adopting of composite material for design of helical coil spring by using glass fiber epoxy resin. The later one had been designed with rectangular cross section. This spring 
was designed for payload $1200 \mathrm{~N}$, and deflection $30 \mathrm{~mm}$ with different wire diameter, coil diameter ,length and deflection and for shear stress allowed $50 \%$ of ultimate tensile strength. So it found that weight reduced by $35 \%$ using combination of convectional steel and composite material and the stiffness may be increased by increasing volume of spring (increase dimension so that weight increase). Sourabh G. et al. (2014).[5] in this study, metal matrix composite had been used in manufacturing of helical spring . aluminum alloy is used because it has high strength, low durability, machinability and availability. AMC225xe is one of the classes of Aluminum matrix composite which has high quality in aerospace application . this grade of Aluminum alloy (AA2124) is reinforced with $25 \%$ by volume of tiny particles of silicon carbide (SiC). Four spring had been designed using AMC and these springs where consider in parallel orientation and for that the total load applied was distributed in to two spring. The design work for load of $800 \mathrm{~N}$ and parallel spring configuration. It was found that weight reduction of the system is reach up to $60 \%$ and the volume of the system is reduced up to $75 \%$ for same loading conditions. Therefore it was found that fatigue strength and performance of suspension system is successfully increased. Ekanthappa J , et al .(2016). [6] in this study, continuous glass fiber and epoxy resin were used to fabricate composite helical coil spring using a special mandrel of mild steel using (spring winding technique).The results of this study load deflection curve is in linear form, The weight of composite FRP helical spring is reduced by $40 \%$ with compare to that weight of steel spring, The stiffness of the composite helical spring with continuous glass fibers was greater that stiffness of steel helical spring for the same dimension, By using two composite helical springs of continuous glass fiber which can support $1120 \mathrm{~N}$ load can effectively be efficiently used for light weight vehicles such as solar vehicles.

Suresh.G, et al (2014) .[7] in this study wovenroving glass fiber epoxy resin and Nano-clay particle (Garamite) . the additive of Nano clay provides unique mechanical and tribological properties combined with low specific weight and a high resistance to degradation in order to ensure safety and economic efficiency. Ten layer of mat had been used to form one spring by filament winding process . after the complete winding of the roving in the profile of the mandrel a small amount of Silica Powder was applied. So on comparing the stiffness of composite spring with steel spring is less and it may be increased by increasing weight of spring. S. N. Gundre and P. A. Wankhade (2013) [8]. this study focused on the finite element analysis of a helical compression spring, that is used in electric three wheelers as per considering various road conditions. the static stress analysis is preformed by finite element analysis to get the Von-Mises stresses and total deflection of helical compression spring at various load.. It was found that maximum shear stress induced in the spring is $1.246 \times 103 \mathrm{MPa}$ and the Von- Mises stress produced is given as
$2.169 \times 103 \mathrm{MPa}$. and for the deformation theoretically is $62.39 \mathrm{~mm}$ higher than numerical deformation 61.77 which is with in permissible limit.

\section{TheoreticalConsideration}

This spring was used in three wheeler shock absorber. The main factors to be consider in spring design is the strain energy of material. There were two types of stresses that acting on spring under compression load, these are direct shear force and torsional stress as described in eq.(1) and shown in Fig.1 [9].Stiffness of spring is also an important parameter in spring design which may be represented as the ratio of load applied to deflection as described in eq.(4) . It depends mainly on shear modulus of materials. The parameters of spring may be changed depending on the application of spring . These parameter were mean diameter, wire diameter, number of active coils and total length. For helical spring there are two factor that effecting the spring design .first shear stress and deflection which may be obtain as the follows and shown in Fig.1 [9]

$$
\begin{gathered}
\tau=K w\left(\frac{8 P D}{\pi d^{3}}\right) \\
K w=\frac{4 C-1}{4 C-4}+\frac{0.612}{2 C} \\
\partial=\frac{8 P D^{3} N}{G d^{4}} \\
K=\frac{F}{\partial}-(4)
\end{gathered}
$$

Where:

$\tau$ : Shear stress

D: Mean diameter $\mathrm{mm}$

$\mathrm{D}:$ Wire diameter $\mathrm{mm}$

C: Spring index

$\mathrm{K}$ : Spring rate $\mathrm{N} / \mathrm{m}$

$\mathrm{K}_{\mathrm{w}}$ : Wahl's factor

2: deflection $\mathrm{mm}$

Rule of mixture : The properties of composites may be estimated by the application of the simple rule of mixture. These rules can be used to estimate average composite mechanical and physical properties in different directions, which may depend on volume fraction.

$$
\begin{aligned}
& \mathrm{E} 11=\mathrm{EfVf}+\mathrm{EmVm}-(5) \\
& \mathrm{E}(\perp)=\frac{\mathrm{Vf}}{\mathrm{Ef}}+\frac{V m}{E m}-(6) \\
& v 12=v f V f+v m V m \\
& \rho c=\rho f * V f+\rho m * V m-(8) \\
& \sigma \mathrm{c}=\sigma \mathrm{f} * \mathrm{Vf}+\sigma \mathrm{m} * \mathrm{Vm} \quad-(9)
\end{aligned}
$$

Where: the subscribe $\mathbf{c}, \mathbf{f}, \mathbf{m}$ represent composite, fiber and matrix

Vf: Fiber volume fraction

Vm: Matrix volume fraction

E: Modulus of elasticity

$\mathrm{v}$ : poisson ratio

$\sigma$ : Strength of material 


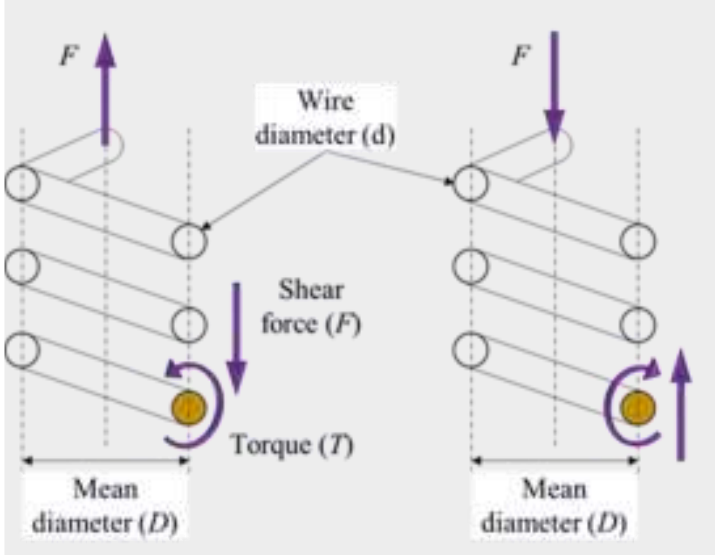

Figure (1) : Stress In Helical Compression Spring Under Axial Load.

The specifications of springs are presented in Table 1

Table (1): Spring Specifications.

\begin{tabular}{|l|c|}
\hline \multicolumn{1}{|c|}{ item } & Value \\
\hline 1. Outer Diameter $\mathrm{D}_{\text {out }}$ & $100 \mathrm{~mm}$ \\
\hline 2.Wier Diameter d & $15 \mathrm{~mm}$ \\
\hline 3. Number of Total Coil, $\mathrm{N}$ & 5 \\
\hline 4. pitch, P & $40 \mathrm{~mm}$ \\
\hline 5. Total Length, L & $170 \mathrm{~mm}$ \\
\hline 6. number of active coils, Nc & 4 \\
\hline
\end{tabular}

\section{Numerical simulation}

\subsection{Modeling}

- In the beginning, defining the properties of composite material to the program through program library. then, build the geometry of spring by SOLID
WORK (2017) through helix and sweep features. The model is created as per the dimension in Table 1 and with plain end and ground. The surface of the spring which are seated are considered as inactive coils as they do not contribute to the deflection and rest. As shown in Fig. 2

- Then, import the geometry to ANSYS to preform analysis. The addition of plates in order to define the boundary conditions.

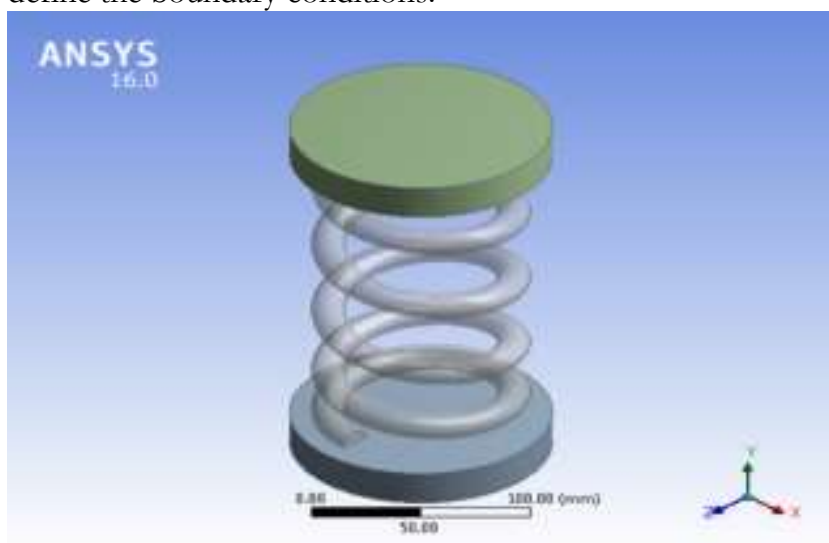

Figure (2): Design of composite spring.

\subsection{Meshing and loading condition:}

After entering the properties of material, the design of model has been loaded to ANSYS WORKBENCH. Then, the mesh is generated as shown in Fig.3. After meshing the boundary condition are applied as shown in Fig. 4. The spring is fixed from the bottom end and load is applied axially in( $y$-direction in compression $)$ at the top end as shown in Fig. 4.

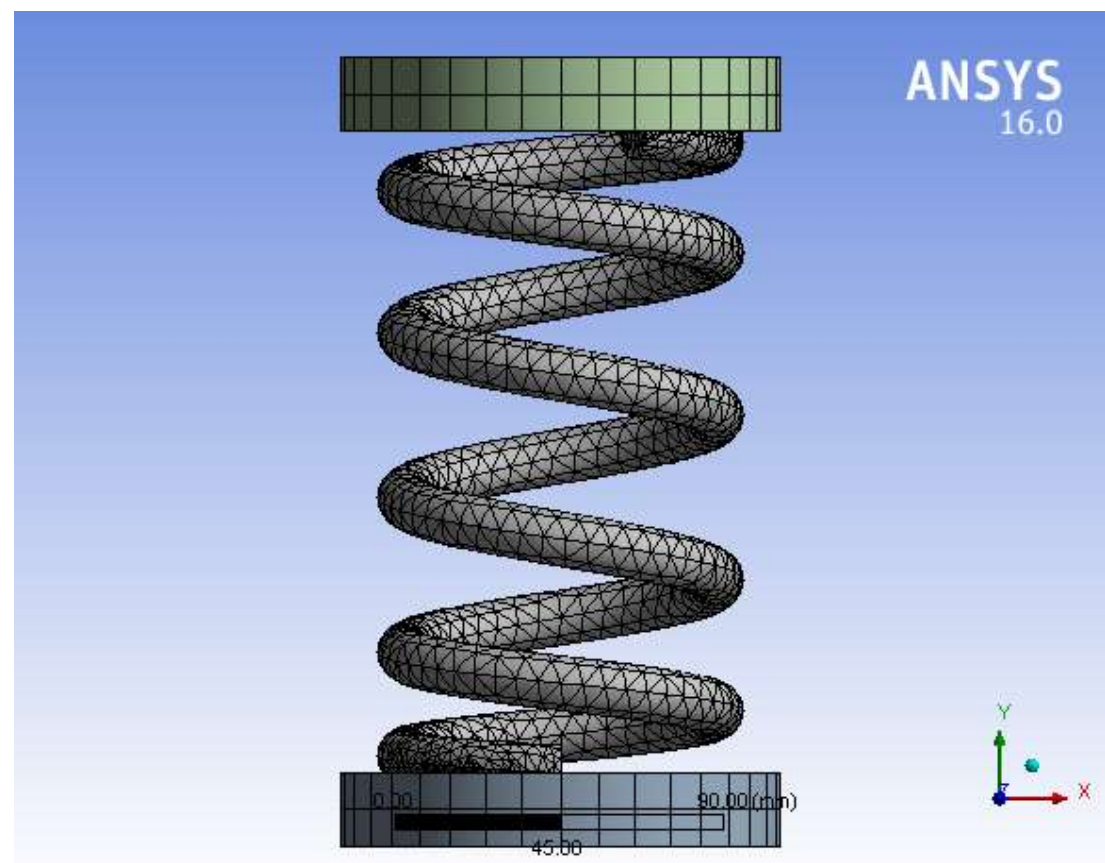

Figure (3): Meshing the Model by ANSYS. 


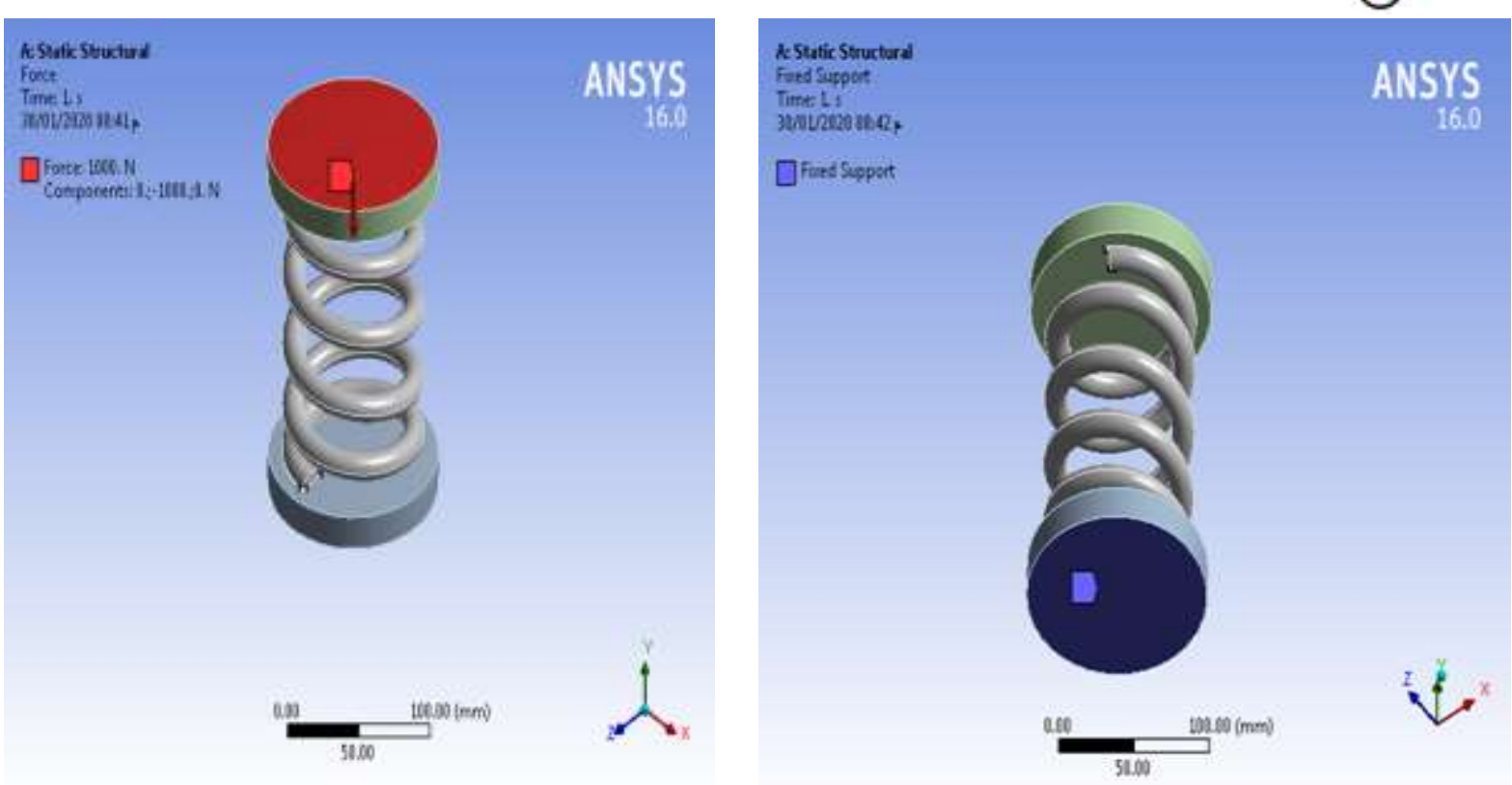

Figure (4): Applied Boundary Condition (Load was Applied Axially in Compression at The Top and Fixed Support from Bottom).

\subsection{Analysis:}

- Static structural analysis: static analysis is carried out to determine the total deformation, equivalent stress, equivalent strain and shear stress under loads $700,800,900$ and $1000 \mathrm{~N}$.

- Also, theoretical analysis had been done by using equation and then compare between the theoretical and numerical results.

\section{Fabrication:}

Manufacturing process of composite helical spring is quite different from manufacturing of steel spring. In this work the filament winding process is used to fabricate helical compression spring. At the beginning plain weave of E-Glass mat had been used in the fabrication process of spring. This mat will be disassembled into single yarns each one of them consist of a small diameter filament that is ranged from $(1-100 \mu \mathrm{m})$. Then, the fibers were collected to form a bundle of fibers which represents wire diameter of spring. After that, the mixture of polyester had been prepared and mixed well to insure there are no bubbles appear in it. Then immerged the bundle of fibers in the mixture and warp it on the internal part of mold as shown in Fig.5. After that it is closed with the outer covering and it is left for 48 hours as curing time. Then open the mold and extract the product as shown in Fig.6. The properties of materials used were listed in Table 2.

Table(2): Properties Of Glass Fiber And Polyester

\begin{tabular}{|l|c|c|}
\hline \multirow{2}{*}{ Properties } & \multicolumn{2}{|c|}{ value } \\
\cline { 2 - 3 } & Glass & polyester \\
\hline Density & $2.5 \mathrm{~g} / \mathrm{cc}$ & $1.2 \mathrm{~g} / \mathrm{cc}$ \\
\hline Poisson ratio & 0.33 & 0.33 \\
\hline Young' modulus & $72 \mathrm{Gpa}$ & $3.1 \mathrm{Gpa}$ \\
\hline Shear modulus & $30 \mathrm{Gpa}$ & $1.1 \mathrm{Gpa}$ \\
\hline Ultimate tensile & $2400 \mathrm{Mpa}$ & $40 \mathrm{Mpa}$ \\
\hline
\end{tabular}
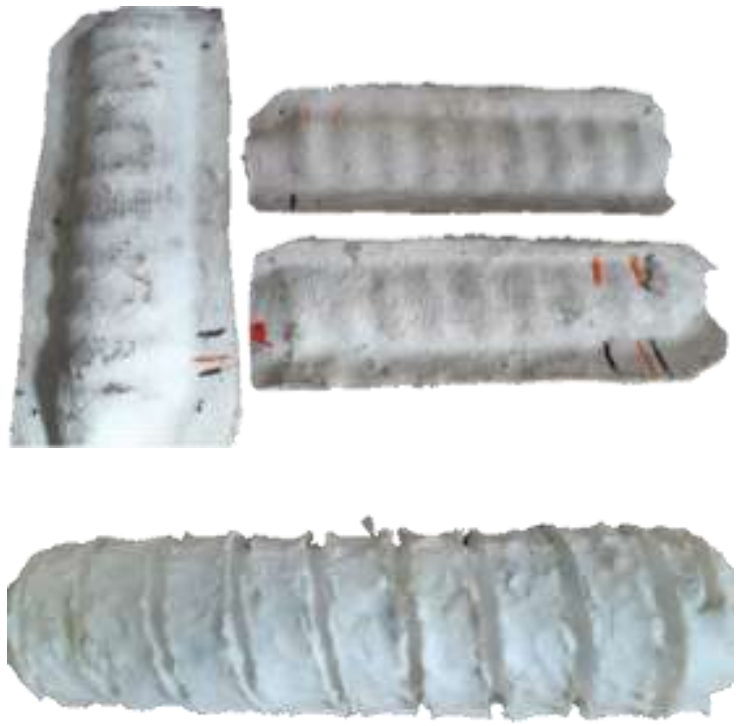

Figure 5 : Internal and The External Parts Of The Mold.

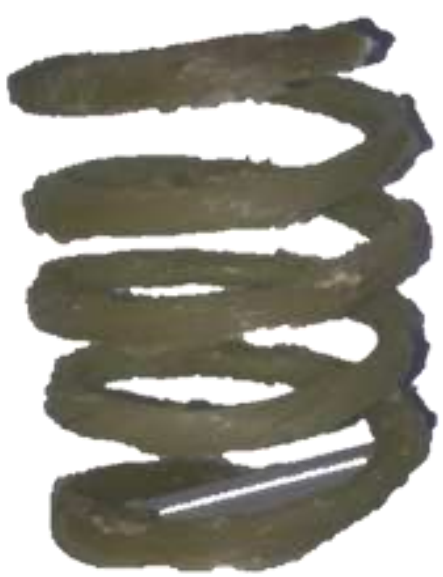




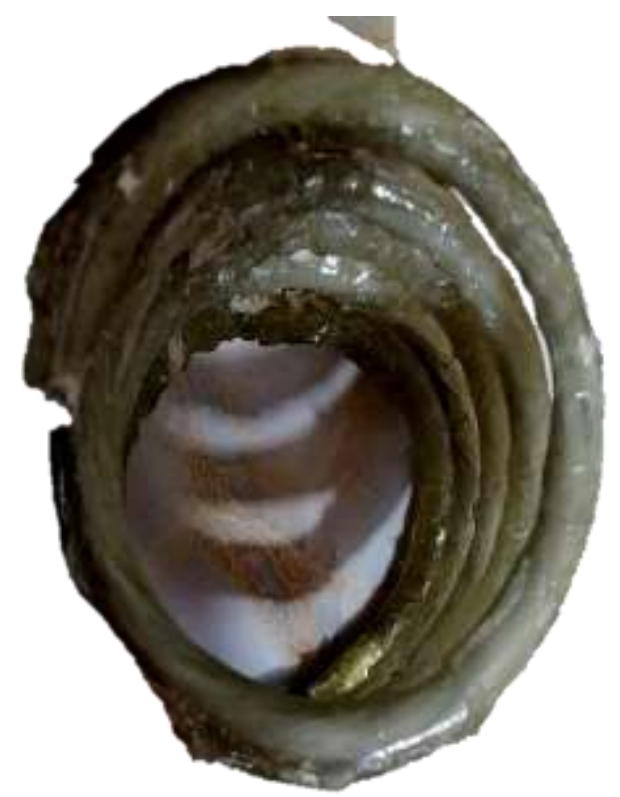

Figure 6: Glass Composite Spring

\section{Results and Discussion}

The theoretical results were prepared due to the equations. These equations were include deflection of spring ,shear stress and stiffness. The load condition applied according to previous research. For the deflection, it shows a linear relationship with load ,as the load increased the deflection also increased .It is depend on the parameters of spring and shear modulus of material. In comparison between theoretical and numerical deflections results of glass fiber composite spring under different loads condition $(700,800,900,1000 \mathrm{~N})$ were higher than deflection of steel spring as described in Tables2 and table 3 and shown in Fig.7and Fig 8 . And because of deflection depends on shear modulus of material so this explain the variation in deflection values steel and glass composite springs . as shown in Fig. 9 and Table 3 and 4 . Maximum Shear stress was distributed at the inner surface of spring as shown in Fig.7and 8 and described in Table 5and 6 with maximum value (101Mpa under load $1000 \mathrm{~N}$ ) for glass composite spring. The behavior composite materials under shear load depend on matrix properties in transferring stresses through the composite layers and for better load transfer the matrix must exhibit good adhesion properties for better wetting of fiber and good mechanical characteristcs. The relation between load and shear stress in both theoretical and numerical results was linear as shown in Fig. 10 .[10] And for stiffness of composite spring is less than steel spring in small portion as shown in Table 7 the theoretical stiffness of two springs were close to each other
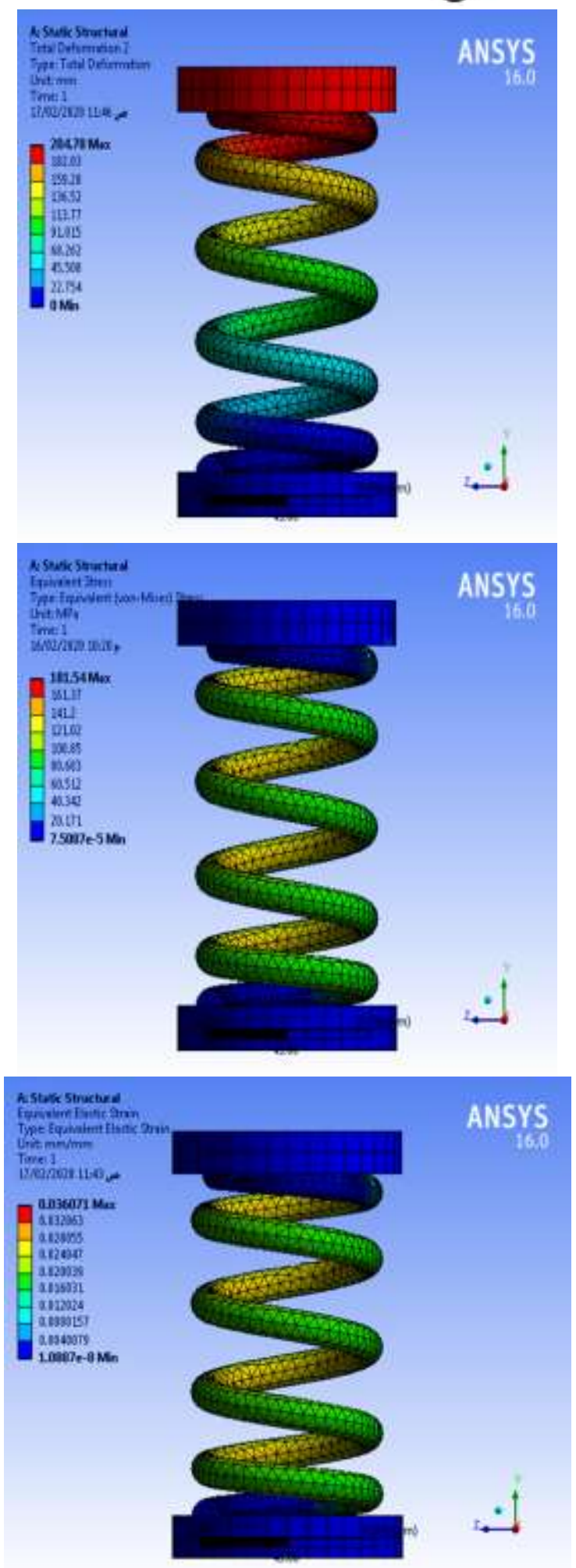


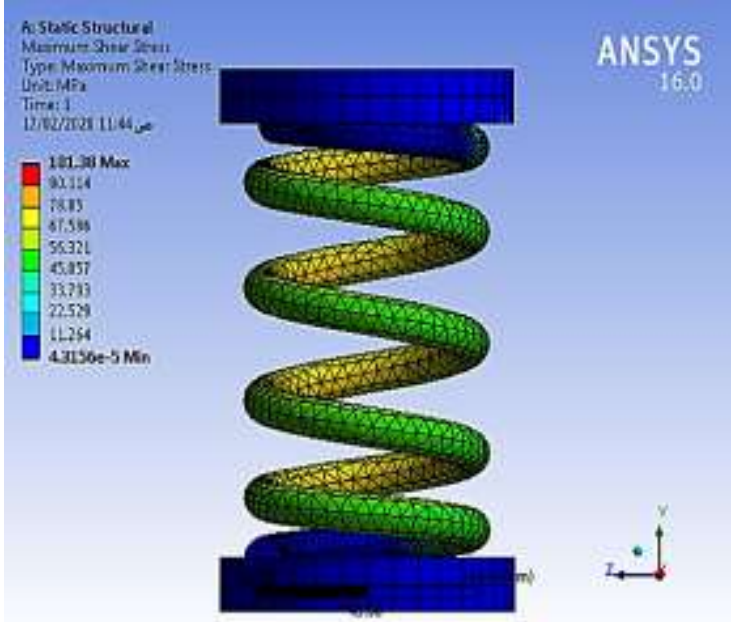

Figure(7) : Numerical Results Of Glass Reinforced Composite Spring Under 1000N
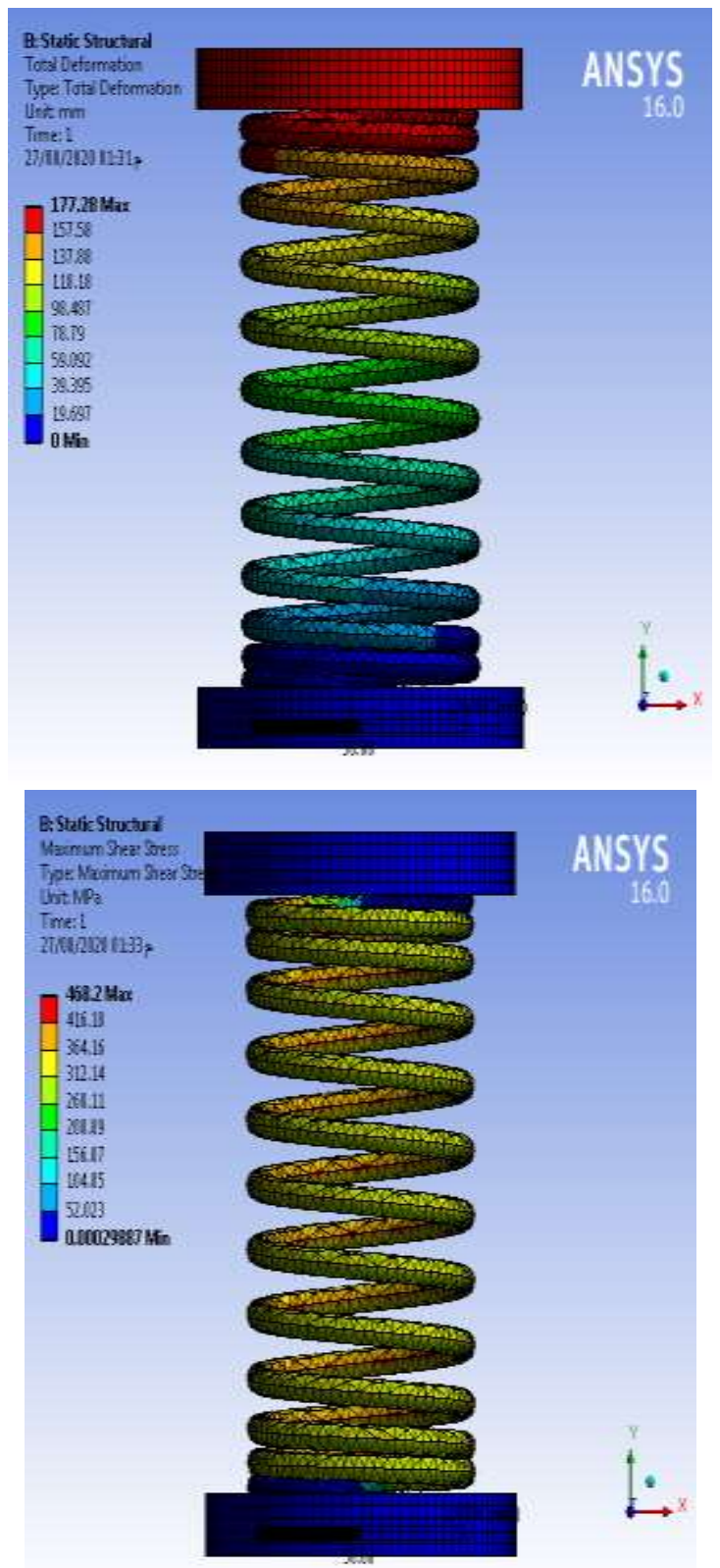

Figure (8): Numerical Results of Steel Spring under load1000 N.
Table (3): Theoretical Results

\begin{tabular}{|c|c|c|}
\hline \multirow{2}{*}{ Load N } & \multicolumn{2}{|c|}{ Deflection mm } \\
\cline { 2 - 3 } & Steel Spring & $\begin{array}{c}\text { E-Glass Composite } \\
\text { Spring }\end{array}$ \\
\hline 700 & 124.1 & 139.45 \\
\hline 800 & 145.654 & 159.41 \\
\hline 900 & 163.681 & 179.1 \\
\hline 1000 & 182.06 & 199.27 \\
\hline
\end{tabular}

Table(4) : Numerical Results

\begin{tabular}{|c|c|c|}
\hline \multirow{2}{*}{ Load N } & \multicolumn{2}{|c|}{ Deflection mm } \\
\cline { 2 - 3 } & Steel Spring & $\begin{array}{c}\text { E-Glass } \\
\text { Composite Spring }\end{array}$ \\
\hline 700 & 124.1 & 143.37 \\
\hline 800 & 141.12 & 163.827 \\
\hline 900 & 159.5 & 184.31 \\
\hline 1000 & 177.28 & 204.2 \\
\hline
\end{tabular}

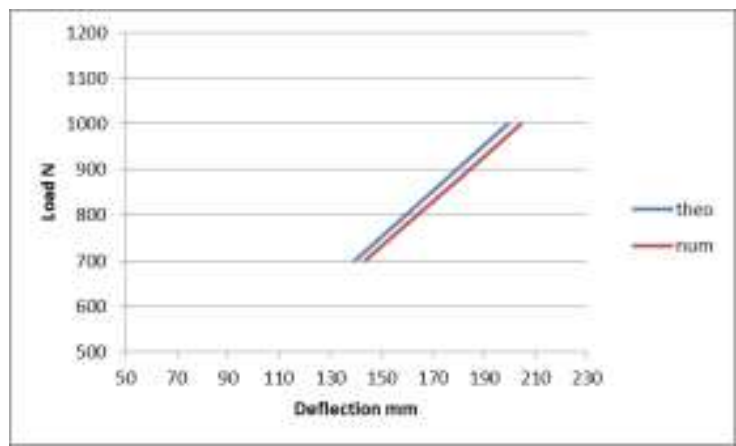

Figure (9): Comparison Between the Theoretical and Numerical Results of Glass Fiber Composite Spring

Shear stress result:

Table (5): Theoretical Results

\begin{tabular}{|l|c|c|}
\hline \multirow{2}{*}{ load } & \multicolumn{2}{|c|}{ Shear stress MPa } \\
\cline { 2 - 3 } & Steel Spring & $\begin{array}{c}\text { Glass Composite } \\
\text { Spring }\end{array}$ \\
\hline 700 & 278.57 & 56.95 \\
\hline 800 & 318.37 & 65.1 \\
\hline 900 & 358.1 & 73.24 \\
\hline 1000 & 397.96 & 81.38 \\
\hline
\end{tabular}

Table (6): Numerical Shear Stress Results

\begin{tabular}{|c|c|c|}
\hline \multirow{2}{*}{ Load N } & \multicolumn{2}{|c|}{ Shear stress MPa } \\
\cline { 2 - 3 } & Steel spring & $\begin{array}{c}\text { Glass Composite } \\
\text { Spring }\end{array}$ \\
\hline 700 & 327.1 & 70.9 \\
\hline 800 & 374.56 & 81.3 \\
\hline 900 & 421.83 & 91.24 \\
\hline 1000 & 468.2 & 101.38 \\
\hline
\end{tabular}




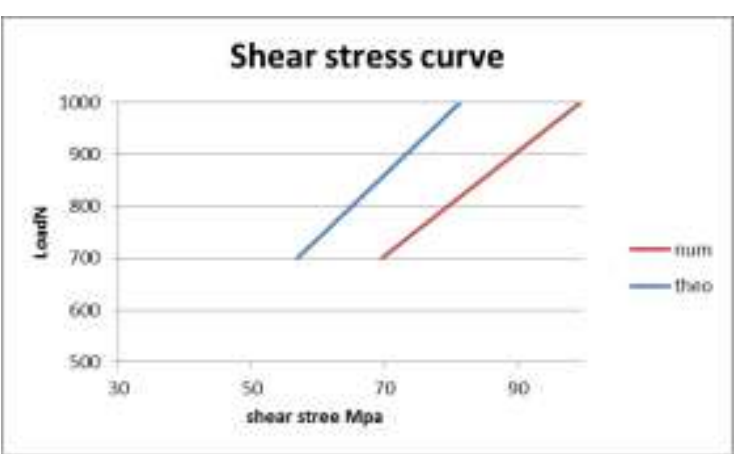

Figure (10): Numerical and Theoretical Results of Shear Stress of Glass Fiber Composite Spring.

Table (7) : Stiffness Result

\begin{tabular}{|c|c|c|}
\hline Item & $\begin{array}{c}\text { Theoretical } \\
\text { Stiffness }\end{array}$ & $\begin{array}{c}\text { Numerical } \\
\text { Stiffness }\end{array}$ \\
\hline $\begin{array}{c}\text { Glass Composite } \\
\text { spring }\end{array}$ & 5.01 & 5.28 \\
\hline Steel Spring & 5.49 & 6.15 \\
\hline
\end{tabular}

\section{Conclusion:}

Composite materials can effectively used in manufacturing of helical spring that is used in special application. Such as spring that is used in suspension system of vehicle without effecting the performance of suspension system. The composite spring can support the different load condition, the weight reduced by $46 \%$ than weight of steel with the same performance results. Composite stiffness smaller than of steel. The deflection of composite spring is higher than that deflection of steel spring under the same load. Cost of composite spring increased by 5 times of steel spring, On the other hand, the difficulty of manufacturing and dealing with composite materials.

\section{References:}

[1] A. Goodarzi , A. Khajepour, Vehicle Suspension System Design and Technology , (2017)., www.morganclypool.com.

[2] C. Onal, S. Ghorbani-Faal, Design And Manufacture of an Adaptive Suspension System, April 30, 2015. http://www.wpi.edu/academics/ugradstudies/projec t-learning.html

[3] M. Klárová , Composite Material, Ostrava 2015. miroslava.klarova@vsb.cz

[4] G. B. Jadhav, V. Gawande, review on development and analysis of helical spring with combination of conventional and composite materials, International Journal of Engineering Research and General Science Volume 3, Issue2, 2015. www.ijergs.org

[5] Sourabh G. Harale, M. Elango, Design of Helical Coil Suspension System by Combination of Conventional Steel and Composite Material, International Journal of Innovative Research in Science Engineering and Technology, volume 3, Issue 8 , Aguset 2014.

www.ijirset.com

[6] J. Ekanthappa, G S Shankar, B M. Amith, M. Gagan, Fabrication and experimentation of FRP helical spring, IOP Conf. Series: Materials Science and Engineering 149, PP.6, (2016). https://iopscience.iop.org/article/10.1088/1757$\underline{\text { 899X/149/1/012098 }}$

[7] G.Suresh, R. Vignesh, B. Aravinth, K. Padmanabhan, A.Thiagararajan, Fabrication and Analysis of Nano Composite Cylindrical Helical Spring , International Journal of Innovative Research in Science, Engineering and Technology, volume 3,Issue 2, PP. 6, (2014) www.ijirset.com

[8] S. N. Gundre, P. A. Wankhade, A Finite Element Analysis Of Helical Compression Spring For Electric Tricycle Vehicle Automotive Front Suspension, International Journal of Engineering Research \& Technology, Vol. 2 Issue 6,(2013). www.ijert.org

[9] Budynas-Nisdett, shigley' Mechanical Engineering Design, (2006) Eighth edition, ISBN: 0-390-76487, http://www.primisonline.com

[10] Soo-Jin Park and Gun-Young Heo, Precursors and Manufacturing of Carbon Fibers, p.239 ISNB:978-94-017-9477-0 (2015). https://link.springer.com/chapter/10.1007/978-94$\underline{017-9478-7 \quad 2}$ 